\title{
Numerical and Experimental Studies of the Analysis of Heat Flow in Building Fires
}

\author{
Lee, Ji-Hee* $\cdot$ Kim, Woo-Suk** $\cdot$ Yeem, Hyo-Jin*** $\cdot$ Kim, Wha-Jung****
}

\begin{abstract}
Presently in most of developed countries, PBD (Performance-Based Design) is actively being adopted to reduce the danger of fire in large, high-rise buildings. In order to do so, prediction and analysis of heat flow must be conducted in advance. This paper has utilized an MPS (Moving Particle Semi-implicit) method to design a 2-Dimensional Heat Flow Analysis Program and conducted an experiment through the use of a reduced-scale model having the same relative parameters of heat source and size. Two separate results of heat flow following a rise in the fire source temperature were cross analyzed to determine correlation.
\end{abstract}

Key words : Heat flow, MPS method, Numerical analysis, Building fires

\section{요 지}

최근 선진국에서는 건축물의 대형화 - 고층화로 인하여 화재 위험성이 증가됨에 따라 성능적 내화설계법을 적극 도입하고 있 다. 이를 위해서는 그 근간이 되는 열 유동에 대한 예측과 분석이 선행되어야 한다. 따라서 본 연구에서는 MPS법을 이용하여 2차원 열 유동 해석 프로그램을 구축하고 동일한 조건의 열원과 크기를 가지는 축소모델 실험을 하였다. 화원의 온도상승으로 인한 공간 내부로의 열 유동 분포를 중심으로 열 유동 해석과 실험 결과값을 비교 · 분석하였다.

핵심용어 : 열 유동, 입자법, 수치 해석, 건물 화재

\section{Introduction}

With the introduction to the construction industry of newly developed materials and technologies concurrent with the increase in new high-rise and multiplex buildings, existing Fire Safety Technology standards are no longer consistent with the state of the art. Developed counties are adopting, PBD (Performance-Based Design) that considers parameters such as type, size and condition of a structure, to predict and evaluate safety during a fire. Like the international trend in fire safety, South Korea is actively preparing for adopting the PBD.

Yet prior to the introduction of PBD, studies on occupant evacuation procedures, fire behaviors of materials in structures, and heat flow analysis during fires have to be conducted. Among these, the heat flow properties are directly related to fire behavior and affects direction in spread of fire. Heat flow is largely affected by such factors as location and size of openings. It can be predicted through numerical analysis.

Thus, this paper wants to design a numerical analysis of heat flow utilizing MPS (Moving Particle Semi-implicit) method, to analyze properties of heat flow during fire and serving as a fundamental material for the application of PBD. Also, this paper wants to experiment reliability of the program by cross analyzing results acquired from experiments conducted.

Present heat flow analysis which has been researched and developed is closely related to fluid flow (Chang et al., 2003). It applies FEM (Finite Element Method) and CFD (Calculus of Finite Differences). The particle method expresses a continuum of a finite number of particles, and calculates movement of the continuum based on the movement of particles. Each particle contains variables such as velocity or pressure. Lattices required during CFD or FEM are not utilized. Therefore, the particle method may make

\footnotetext{
*Member. Research Professor, School of Architecture and Civil Engineering, Kyungpook National University(E-mail: jihee@knu.ac.kr)

**Corresponding Author. Member. Research Professor, School of Architecture and Civil Engineering, Kyungpook National University

(Tel: +82-53-950-5596, Fax: +82-53-950-4767, E-mail: kimw@knu.ac.kr)

***Former Master Student, School of Architecture and Civil Engineering, Kyungpook National University

**** Professor, School of Architecture and Civil Engineering, Kyungpook National University
} 
unnecessary the complex tasks involved in lattice generation. MPS method is a particle method applied with a calculation algorithm for incompressible fluid which is represented by moving particles (Koshizuka and Oka, 1996; Koshizuka et al., 1998). There is various research actively being conducted on simple fluid through the use of MPS method. However, there are few studies being conducted on heat flow that can be applied to building fires. Heat flow can be easily calculated by the motion of these particles. Therefore, this paper seeks to analyze heat flow by utilizing MPS method.

This study had been conducted in following manner. A program algorithm has been determined by applying the MPS method, and a 2 dimensional heat flow analysis program based on this algorithm has been designed. During the designing of the analysis program, GUI (Graphical User Interface) environment has been augmented to allow multiple tasks to be executed for input, output and program execution. In addition, a numerical analysis having same parameters as the actual experiment has been conducted to verify the reliability of the program. These two results were cross analyzed for verification.

\section{Numerical Method}

\subsection{Control equation (Koshizuka, 2002)}

- Law of conservation of mass (continuous equation)

$$
\frac{\Delta \rho}{\Delta t}=0
$$

- Law of conservation of momentum (Navier-Stokes equation)

$$
\frac{D u}{D t}=-\frac{1}{\rho} \nabla P+v \nabla^{2} u+g \beta\left(T-T_{0}\right)
$$

- Law of conservation energy

$$
\frac{D T}{D t}=\frac{k}{\rho C_{p}} \nabla^{2} T
$$

where, $\rho$ : Density $\left(\mathrm{kg} / \mathrm{m}^{3}\right)$

$$
\begin{aligned}
& P \text { : Pressure }(\mathrm{Pa}) \\
& v: \text { Kinematics viscosity }\left(\mathrm{m}^{2} / \mathrm{s}\right) \\
& \beta \text { : Heat expansion }\left(1 /{ }^{\circ} \mathrm{C}\right) \\
& T: \text { Temperature }\left({ }^{\circ} \mathrm{C}\right) \\
& T_{0} \text { : Base temperature }\left({ }^{\circ} \mathrm{C}\right) \\
& g: \text { Gravitational acceleration }\left(\mathrm{m} / \mathrm{s}^{2}\right) \\
& k: \text { Heat conduction ratio }\left(\mathrm{kcal} / \mathrm{m} \cdot \mathrm{s} \cdot{ }^{\circ} \mathrm{C}\right) \\
& C_{p}: \text { Specific heat }\left(\mathrm{kcal} / \mathrm{kg} \cdot{ }^{\circ} \mathrm{C}\right)
\end{aligned}
$$

In the MPS method, an interaction model for differential operators such as gradient, divergence and Laplacian are designed for each particle. These are in the form of discrete differential equations. Also, a weight function is applied to the interaction model among particles.

- Weight function

$$
\omega(r)=\left\{\begin{array}{l}
\frac{r_{e}}{r}-1\left(0 \leq r \leq r_{e}\right) \\
0\left(r_{e} \leq r\right)
\end{array}\right.
$$

where, $r$ : Distance between particles

The sum of the weight function between particle and a nearby particle $j$ is referred to as particle density. When the mass of particles is constant, the particle density becomes proportional to density of fluid.

- Particle density

$$
n_{i}=\sum_{j \neq i} \omega\left(\left|\mathbf{r}_{i}-\mathbf{r}_{i}\right|\right)
$$

where, r: Position vector

The control equations (1) and (2) include gradient and Laplacian models as differential operators. An interaction model between particles of these two differential operators is needed. The following equations are for gradient and Laplacian models of MPS method.

- Gradient model

$$
\langle\nabla \phi\rangle_{i}=\frac{d}{n^{0}} \sum_{j \neq i}\left[\frac{\phi_{j}-\phi_{i}}{\left|\mathbf{r}_{j}-\mathbf{r}_{i}\right|^{2}}\left(\mathbf{r}_{j}-\mathbf{r}_{i}\right) \omega\left(\mid \mathbf{r}_{j}-\mathbf{r}_{i}\right)\right]
$$

- Laplacian model

$$
\left\langle\nabla^{2} \phi\right\rangle_{i}=\frac{2 d}{\lambda n^{0}} \sum_{j \neq i}\left[\left(\phi_{j}-\phi_{i}\right) \omega\left(\left|\mathbf{r}_{j}-\mathbf{r}_{i}\right|\right)\right]
$$

where, $d$ : Number of dimensions

$$
n^{0} \text { : Particle density }
$$

Coefficient $\lambda$ is introduced here to unify increase in statistical decentralization in the solution of the analysis. Definition of $\lambda$ is as follows. Here, to eliminate space occupied by particle $i$ in integration $r_{0}$ becomes $\pi\left(r_{0}\right)^{2}=l_{0}^{2}$. Initial distance among particles is denoted by $l_{0}$.

$$
\lambda=\frac{2 \pi\left(\frac{r_{e}^{4}}{12}-\frac{r_{e} r_{0}^{3}}{3}+\frac{r_{0}^{4}}{4}\right)}{2 \pi\left(\frac{r_{e}^{2}}{2}-r_{e} r_{0}+\frac{r_{0}^{2}}{2}\right)}
$$

\subsection{Calculation algorithm}

In the control equation, pressure gradients of the continuous equations and the Navier-Stokes equations are analyzed implicitly, while viscosity and gravity are analyzed explicitly. By utilizing these, unknown velocity $\mathbf{u}^{*}$ and location $\mathbf{r}^{*}$ of a particle can be acquired.

$$
\begin{aligned}
& \mathbf{u}^{*}=\mathbf{u}^{k}+\Delta t\left[\nu \nabla^{2} \mathbf{u}+\mathbf{g} \beta\left(T-T_{0}\right)\right]^{k} \\
& \mathbf{r}^{*}=\mathbf{r}^{k}+\Delta t \mathbf{u}^{*}
\end{aligned}
$$


Following equations are used to acquire particle density, velocity, location and temperature when visibility is at $k+1$.

$$
\begin{aligned}
& n^{0}=n^{k+1}=n^{*}+n^{\prime} \\
& \mathbf{u}^{k+1}=\mathbf{u}^{*}+\mathbf{u}^{\prime} \\
& \mathbf{r}^{k+1}=\mathbf{r}^{*}+\Delta t \mathbf{u}^{\prime} \\
& \mathbf{u}^{\prime}=-\frac{\Delta t}{\rho_{0}} \nabla P^{k+1} \\
& T^{k+1}=T^{k}+\Delta t\left[\frac{k}{\rho C_{p}} \nabla^{2} T\right]^{k}
\end{aligned}
$$

Adjusted rate of velocity and particle density can be expressed by density conservation equation for pressurized flow. When the density reaches a certain value, the density of fluid becomes proportional to particle density. Here, adjusted rate of particle density, $n^{\prime}$, is generated by adjusted rate of velocity, $\mathbf{u}^{\prime}$. A simultaneous calculation on these is then conducted against time discretely.

$$
\frac{n^{\prime}}{n^{0} \Delta t}+\nabla \cdot \mathbf{u}^{\prime}=0
$$

By substituting the equation (14) for the equation (16), we can acquire a simplified Poisson equation.

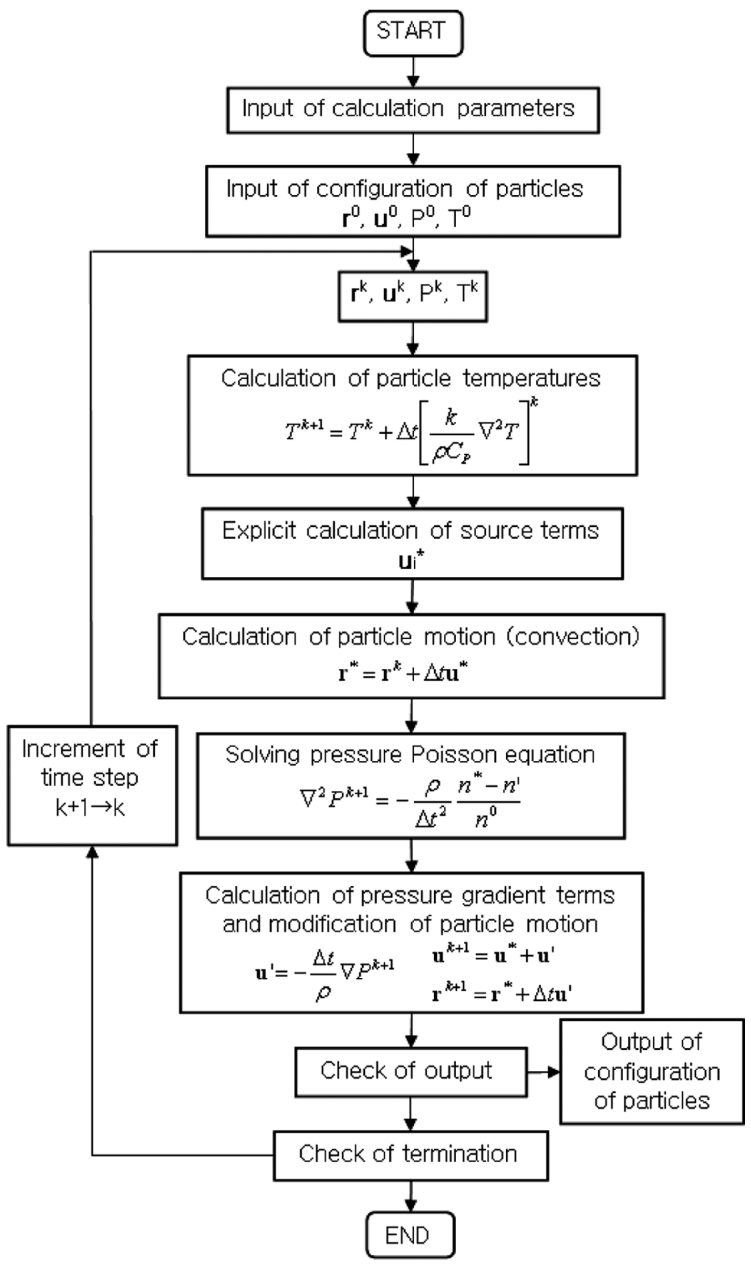

Fig. 1. Calculation algorithm

$$
\nabla^{2} P^{k+1}=-\frac{\rho_{0}}{\Delta t^{2}} \frac{n^{*}-n^{0}}{n^{0}}
$$

The Fig. 1 shows calculation algorithm of the program.

\subsection{Boundary conditions}

The MPS method utilizes particle density in free surface conditions. When the time $k$ had ended, all particles satisfying the following equation (18) are judged to be present in free surface.

$$
n_{j}^{*}<\beta n^{0}
$$

Here, $\beta$ is set at 0.97 .

In solving the simplified Poisson equation, the value of this particle is fixed as $P_{i}^{k+1}=0$.

On the wall boundary, wall particles with fixed coordinate are placed. The wall particles can be classified in to 2 types. Pressure is calculated for internal surfaces contacting fluid particles; pressure calculation is not conducted for external surfaces. Internal wall particles are applied with pressure calculation and fluid particles near the wall get bounced from the wall. Also the same volume of particles existing through an opening through convection, get induced back to the area, creating an air circulation within the area.

\section{Computational Example}

\subsection{Target and methodology of the experiment}

A physical model of a single room having width of $3 \mathrm{~m}$, length of $5.4 \mathrm{~m}$ and height of $3.9 \mathrm{~m}$, with an opening on one side with dimension of width of $0.9 \mathrm{~m}$ and height of $2.1 \mathrm{~m}$ was designed. A scaling law of 1:5 had then been applied to design a smaller scale model. Fig. 2(a) shows full-scale model and Fig. 2(b) shows a reduced-scale model. Table 1 shows scaling law applied in this paper. As part of the numerical research (John and Battaglia, 2004), scaling lows were considered as a viable approach for the simulations. One concern is that simulating the full-scale fire will be computationally expensive and restrict the number of grid

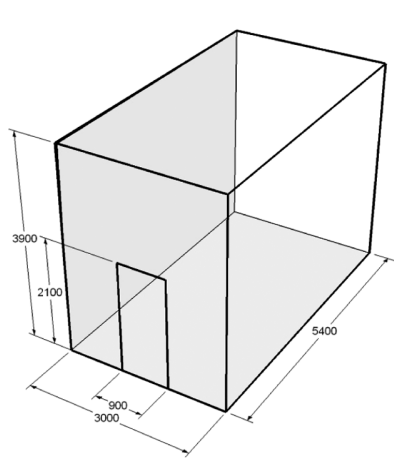

(a) Full-scale

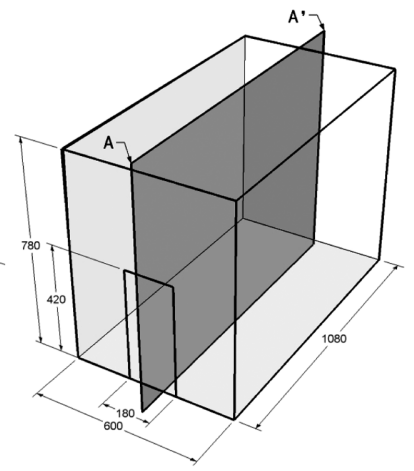

(b) Reduced-scale
Fig. 2. Model scale 
cells needed to adequately resolve the physical features of the flow. Scaled-down experiments and numerical simulations are commonly used as less expensive (monetarily and computationally) alternatives to full-scale modeling. However, the scaled-down model must accurately represent a full-scale fire scenario. In order to ensure that a scale model exhibits the same behavior as the full-scale model, a mathematical correlation must exist between primitive variables. Scaling laws for fires were developed by Byram (1966) using $\pi$-term techniques for heat release rates:

$$
\begin{aligned}
& \frac{L_{m}}{L_{f}}=\frac{D_{h, m}}{D_{h, f}}=\left[\frac{\dot{Q}_{m}}{Q_{f}}\right]^{2 / 5} \\
& \frac{V_{m}}{V_{f}}=\left[\frac{L_{m}}{L_{f}}\right]^{1 / 2}
\end{aligned}
$$

where $m$ denotes model; $f$ denotes full scale; $L$ is length of the flame; $D_{h}$ is hydraulic diameter at the base of the fire; $\dot{Q}$ is total rate of heat output; $V$ is Froude number for velocity (Ko et al., 2010).

A vertical surface was designed crossing both heat source and opening, like the A-A' surface of Fig. 2(b). Thermocouples had been installed at 9 locations for measuring temperature changes over time.

Table 1. Similitude law

\begin{tabular}{|c|c|c|c|}
\hline Classification & Full-scale & Reduced-scale & \\
\hline $\begin{array}{c}\text { Geometric } \\
\text { similarities }\end{array}$ & $L$ & $L^{\prime}=(1 / 5) \times L$ & $0.2 \mathrm{~L}$ \\
\hline Heat release rate & $Q$ & $Q^{\prime}=\left(L^{\prime} / L\right)^{5 / 2} \times Q$ & $0.01789 \mathrm{Q}$ \\
\hline Airflow velocity & $V$ & $V^{\prime}=\left(L^{\prime} / L\right)^{1 / 2} \times V$ & $0.447 \mathrm{~V}$ \\
\hline Airflow temperature & $\theta$ & $\theta^{\prime}=\theta$ & $\theta$ \\
\hline Elapsed time & $t$ & $t^{\prime}=\left(L^{\prime} / L\right)^{1 / 2} \times t$ & $0.447 \mathrm{t}$ \\
\hline
\end{tabular}

- Material used for the model: $1^{\text {st }}$ grade fire resistant gypsum board with thickness of $15 \mathrm{~mm}$

- Fire load: $60 \mathrm{~kg} / \mathrm{m}^{2}$

- Experiment duration: 30 minutes

- Thermocouple: K-type Ø-0.60 mm

- Measurement equipment: ALMEMO 5590, Infrared camera, Digital camera

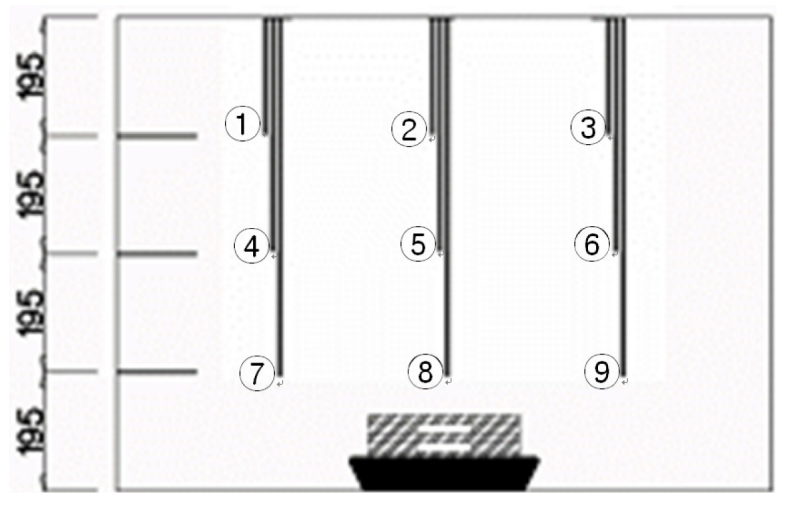

Fig. 3. Thermocouple position
Fig. 3 shows the positions of thermocouples installed on vertical surface.

\subsection{Example of program execution}

Fig. 4 shows a user interface for the numerical analysis allowing input of data such as geometric data, physical properties and temperature of heat source over time. When all necessary data had been input, a model shown in Fig. 5 is automatically generated. Table 2 shows temperature of heat source over time utilized by the program.

\subsection{Result analysis}

Fig. 6 shows a graph on time-temperature curve of thermocouples. As we can see from the graph, no rapid flashover had been found. In addition, the maximum temperature had been shown at 796 seconds and the temperature at the time was $880^{\circ} \mathrm{C}$.

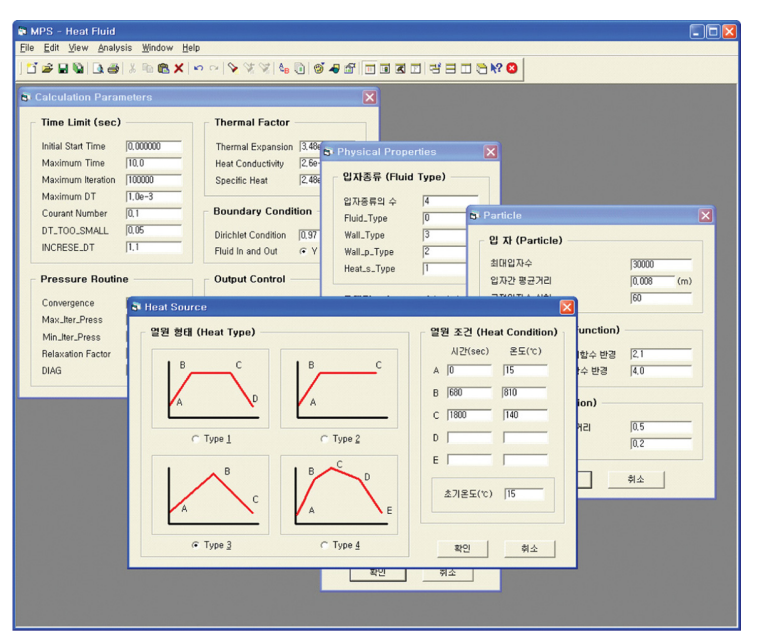

Fig. 4. Input

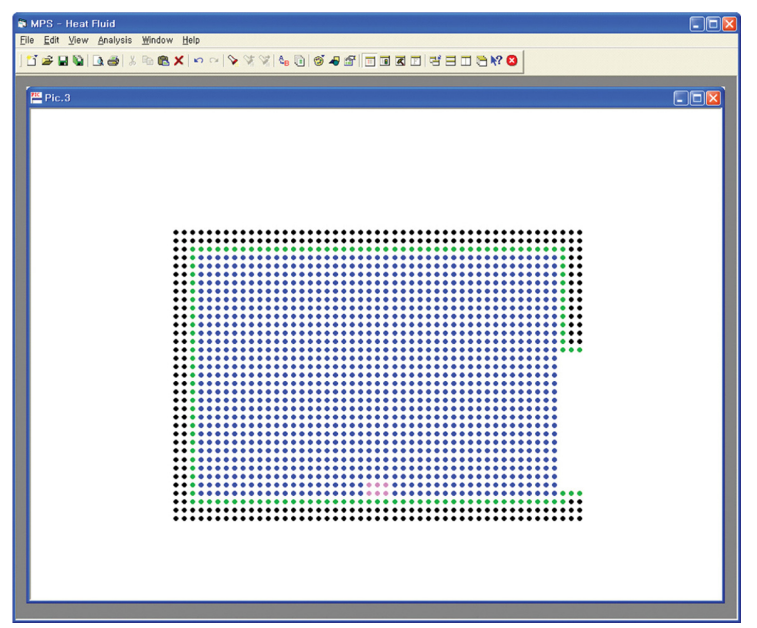

Fig. 5. Modeling

Table 2. Temperature according to time

\begin{tabular}{|c|c|c|c|}
\hline Time $(\mathrm{sec})$ & 0 & 680 & 1800 \\
\hline Temperature $\left({ }^{\circ} \mathrm{C}\right)$ & 15 & 810 & 140 \\
\hline
\end{tabular}




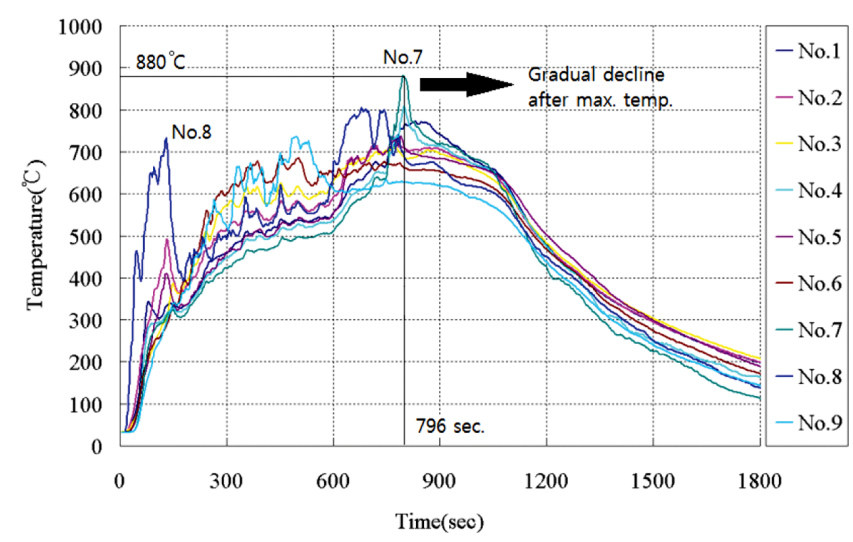

Fig. 6. Time-temperature curve

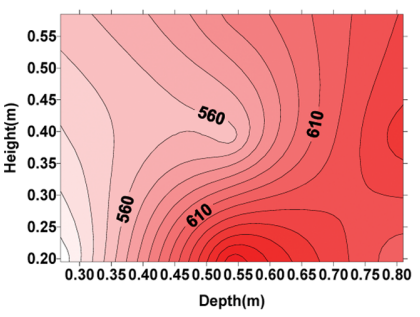

(a) Experiment

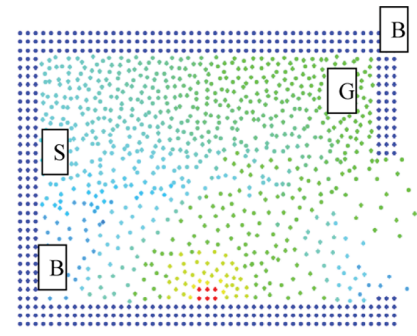

(b) Analysis
Fig. 7. Experimental \& analysis results (10 min.)

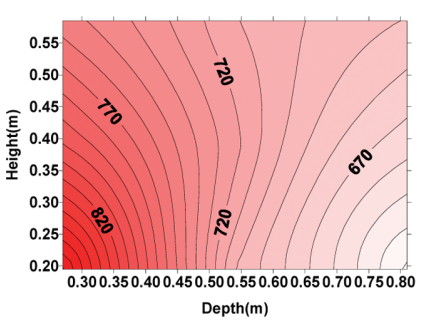

(a) Experiment

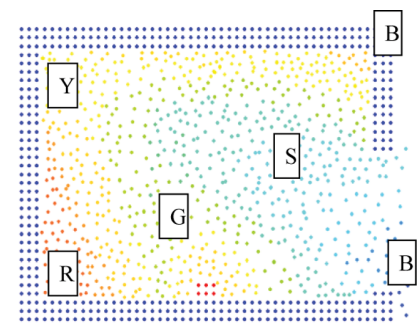

(b) Analysis
Fig. 8. Experimental \& analysis results (peak)

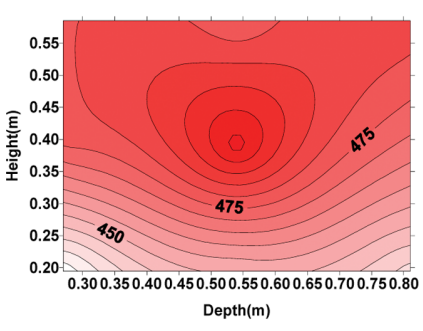

(a) Experiment

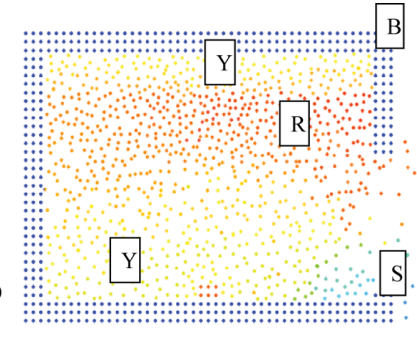

(b) Analysis
Fig. 9. Experimental \& analysis results $(20 \mathrm{~min}$.)

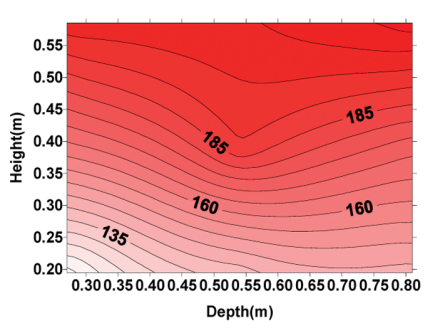

(a) Experiment

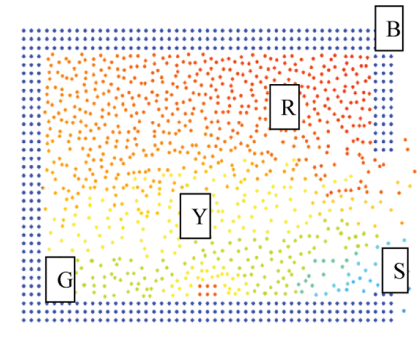

(b) Analysis
Fig. 10. Experimental \& analysis results (30 $\mathrm{min}$.)
Fig. 7 Fig. 10 show results acquired from the actual experiment and program execution for comparing temperature distribution on the vertical surfaces.

Where $\underline{\boldsymbol{B}}$ denotes blue color; $\underline{\boldsymbol{G}}$ denotes green color; $\underline{\boldsymbol{R}}$ senotes red color; $\underline{\boldsymbol{S}}$ denotes sky-blue color; Y denotes yellow color.

Times chosen for temperature distribution comparison were at 10 minutes, peak (13 minutes 16 seconds), 20 minutes and 30 minutes, respectively.

In the experimental results for changes in internal heat flow, heat flow shifts from opening to the vertical center of the room during the development till peak time. From the peak time to declination time, high temperature heat flows from center of the room to upper surface of the room. That is, cold air induced from the bottom of the opening shifts towards the center in clockwise direction, creating a spiral flow. Then it exists through the upper surface of the opening as it gets heated. Analysis results shows very similar results as the result acquired from the actual experiment and we can clearly see that the heat flows in order lower opening, lower surface of the room, center of the room and upper surface of the opening.

\section{Conclusion}

This paper has developed a 2 dimensional heat flow analysis program using MPS method. To examine the reliability of the program, researchers designed a reduced scale model having the same parameters of heat sources and model dimension. The result of an actual experiment has shown very close results to that which had been analytical predicted by the program, allowing researchers to confirm the possibility of applying MPS methodology to heat flow. However, two-dimensional analysis as presented by researchers may not provide an accurate heat flow in indoor areas due to the complex interactions of airflows from many connected rooms. These problems may be solved in future by developing a three-dimensional analysis program. In addition, the program designed by researchers shall be developed further for analyzing complex conditions such as current, humidity, etc. that affects temperature changes in heat flow.

\section{Acknowledgements}

This work was supported by the innovations in Nuclear Power Technology of the Korea Unstitute of Energy Technology Evaluation and Planning (KETEP) grant (Code\# 09' R\&D A01) funded by the Korea government Ministry of Knowledge Economy, and grant from High tech Urban Development Program funded by Ministry of Land, Transportant and Maritime Affairs of Korean government. 


\section{References}

Byram, G.M. (1966) Scaling laws for modeling mass fires, Pyrodynamics, 4, pp. 271-284.

Chang, C., Banks, D. and Meroney, R.N. (2003) Computational fluid dynamics simulation of the progress of fire smoke in large space, building atria, Tamkang Journal of Science and Engineering, 6, pp. 151-157.

John, H.M. and Battaglia, F., (2004) A computational study on the use of balconies to reduce flame spread in high-rise apartment fires, Fire Safety Journal, 39, pp. 277-296.

Ko, G.H., Kim, S.R. and Ryou, H.S. (2010) An experimental study on the effect of slope on the critical velocity in tunnel fires,
Journal of Fire Sciences, 28, pp. 27-47.

Koshizuka, S. (2002) Numerical analysis of flow using particle method, Fluid Dynamics Research, 21, pp. 230-239.

Koshizuka, S., Nobe, A. and Oka, Y. (1998) Numerical analysis of breaking waves using the moving particle semi-implicit method, International Journal of Numerical Method in Fluid, 26, pp. 751-769.

Koshizuka, S. and Oka, Y. (1996) Moving-Particle Semi-implicit Method of Fragmentation of Incompressible Fluid, Nuclear Science Engineering, 123, pp. 424-434.

Received February 1, 2013

Revised February 13, 2013

(C) Accepted February 27, 2013 